\title{
Narcissism, risk and uncertainties: analysis in the light of prospect and fuzzy-trace theories
}

Márcia Figueredo D'Souza

Departamento de Ciências Humanas e Tecnologia, Universidade Estadual da Bahia, Camaçari, Brasil, and

Gerlando Augusto Sampaio Franco de Lima

Department of Accountancy, University of Illinois at Urbana-Champaign, Champaign, Illinois, USA
Narcissism, risk and uncertainties

Received 31 October 2019 Revised 27 January 2020 9 June 2020 Accepted 6 September 2020

\begin{abstract}
Purpose - This study aims to analyze the relationship between the nonpathological traits of narcissism and decisions under conditions of uncertainty and risk in light of the prospect (PT) and fuzzy-trace theories (FTT).

Design/methodology/approach - This paper conducted an empirical-theoretical study with 210 Brazilian academics from the business area (accountants and managers), using a self-reported questionnaire to collect data. This paper analyzed the data through descriptive statistical techniques, correlation, test of hypotheses and logistic regression.

Findings - The results point to a lower disposition of respondents to narcissistic traits, although the characteristics of self-sufficiency, authority, exploitation and superiority have been demonstrated. Most participants chose the sure gain in positive scenarios and risk in light of possibility of losses. However, those with high levels of narcissism showed higher propensity to make risky decisions, both in positive and negative scenarios.
\end{abstract}

Research limitations/implications - The empirical results about risky decision-making behavior of individuals with narcissist traits spur further investigation on the impacts of attitudes and behaviors in organizations as they are affected by psychosocial factors. These attitudes and behaviors, reflected in administrative and financial reports, influence future decisions of investors.

Originality/value - The interaction between the areas of business administration and psychology in regard to the effects of the narcissist personality trait and the FTT is both original and valuable for the business area. The simplest scenario based on the FTT theory can help eliminate issues around the interpretation and complexities of calculations regarding decision-making scenarios in PT format.

Keywords Narcissism, Prospect theory, Fuzzy-trace theory

Paper type Research paper

(C) Márcia Figueredo D’Souza and Gerlando Augusto Sampaio Franco de Lima. Published in RAUSP Management Journal. Published by Emerald Publishing Limited. This article is published under the Creative Commons Attribution (CC BY 4.0) license. Anyone may reproduce, distribute, translate and create derivative works of this article (for both commercial and non-commercial purposes), subject to full attribution to the original publication and authors. The full terms of this license may be seen at http://creativecommons.org/licences/by/4.0/legalcode

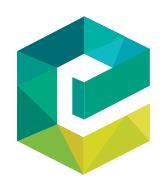

RAUSP Management Journal Vol. 56 No. 1,2021 pp. $129-147$

pp. 129-147
Emerald Publishing Limited 2531-0488 
RAUSP

56,1

\section{Introduction}

In the business arena, executives make financial decisions to organize, control, leverage and improve business performance. These decisions are reflected in the accounting reports and in the continuity of the company. At times, executives make impulsive, risky and even fraudulent choices to present positive results, sometimes without thinking through the future consequences and implications of these acts in the long run.

Executives' impulsive behavior and pleasure in taking risks can be associated with subjective factors, including narcissistic personality traits. Executives with high traits of narcissism make risky decisions and gambles to gain admiration and praise for their performance. For Amernic and Craig (2010) and Olsen, Dworkis, and Young (2014), the achievement of high corporate profits is the business card of these managers. They influence the work team to adopt an opportunistic attitude and make unethical decisions to inflate business profit so that the company's success becomes a steppingstone for their greater professional growth. When narcissistic executives see photos and stories of successful executives, the narcissists are motivated to commit acts and make choices without measuring the consequences, so that they, too, can be admired by others.

Individuals with nonpathological traits of narcissism are characterized by an excess of superiority, self-sufficiency, authority, vanity, exhibitionism, exploitation and a sense of entitlement (Raskin \& Terry, 1988). Narcissism has been the subject of studies on marketing strategy (Reche, Bertolini, \& Debona, 2020), the need for power (D'Souza, Oliveira, Almeida, \& Natividade, 2019), profile analyses of accounting students (Lima Filho, de Souza, \& D'Souza, 2019), cultural values of accounting students (D'Souza \& Lima, 2019), career choices in accounting (D'Souza \& de Lima, 2018), academic performance (Lima, Avelino, \& Cunha, 2018), discourse analysis in administrative reports of companies involved in financial scandals (D'Souza, Aragão, \& De Luca, 2018) and academic dishonesty (Avelino \& de Lima, 2017).

In studies involving decisions, Yang, Sedikides, Gu, Luo, Wang, and Cai (2018); Meisel, Ning, Campbell, and Goodie (2015); and Buelow and Brunell (2014) investigated risky decision-making and overconfidence, and Buyl, Boone, and Wade (2017) discussed risky decisions regarding corporate governance. Most of these studies on risky decision-making use the prospect theory (PT) as enunciated by Kahneman and Tversky (1979).

According to these authors, decision-making involves preferences that change in the face of positive scenarios (gains) and negative scenarios (losses). Most decision-makers prefer certainty when choosing games, a phenomenon called the certainty effect (or risk aversion). However, individuals change their preferences to the risky option when the possible outcomes involve losses; therefore, there is no unanimity to risk aversion. The shift from risk aversion to risk seeking is called the reflection or framing effect (Kühberger \& Tanner, 2010; Reyna \& Brainerd, 1995).

However, another theoretical approach also stood out when using, in an adapted way, the decision problem of the PT. Reyna and Brainerd $(1991,1995)$ found that neither numerical information was necessary nor was it sufficient to produce phenomena of decision framing, given that the memory used to solve problems is represented by two systems: the essence (gist) and the literal (verbatim). Individuals undergoing memory tests are more likely to use literal memory immediately; however, after some time, they switch to the essence memory, which is more diffuse and less precise than literal memory. In this vein, the authors created the fuzzy-trace theory (FTT).

The PT and FTT make the same predictions about the classic framing effect, the former using situations that refer to calculations while the latter does not. When the results are compared by the two theories, Kühberger and Tanner (2010) assert that, in the experiment 
based on the FTT, the results were of greater magnitude when the numbers were absent than when they were present.

In view of this contextualization, this paper intends to elucidate the following research problem: What is the relationship between narcissistic traits and decision-making in conditions of uncertainty and risk? We analyze the relationship between narcissism and the framing effect, in light of the PT and the FTT. With this in mind, we surveyed 210 academics in the business arena (accountants and administrators).

The results of the study contribute in theoretical, methodological and practical ways.

Narcissism, risk and uncertainties Theoretically, for allowing the dialogue between the areas of accounting, business administration and psychology, which is still little explored regarding the effects of the narcissistic personality trait and the PT and FTT, especially in the business arena. Our discussion fills a theoretical gap, given that previous discussions about personality traits and the FTT have focused on analyzing HEXACO's personality traits (honesty-humility, emotivity, extroversion, agreeableness, conscientiousness and openness) (Brunot \& Brunot, 2017).

Similarly, most of the personality studies that underpinned investigations into the PT discussed the features of the Big Five (Lauriola \& Levin, 2001), HEXACO (Soane \& Chmiel, 2005; Weller \& Thulin, 2012) and types of Jungian personalities, extroversion and introversion (Braga, 2015).

Furthermore, studies on decision-making and narcissism that developed empirical applications in a national context have discussed opportunistic decisions, with manipulation or management of results (D'Souza, Lima, Jones, \& Carre, 2019; Góis, 2017; D'Souza, 2016; D'Souza \& Lima, 2015), analyzing, in addition to the narcissistic trait, other dark personality traits: Machiavellianism, psychopathy and sadism.

Therefore, the importance of studying the two theories lies in stimulating more foreign studies and national discussions of risky decision-making and in empirically comparing results of the FTT and PT.

Methodologically, our scenarios based on the FTT can help executives eliminate problems of interpretation and complex decision-making scenarios.

Furthermore, our study inspires a practical analysis of the magnitude of the results, especially when respondents are faced with profit and loss scenarios, with the same objective (one involving numbers and calculations, while the other does not). This analysis will help decision-makers understand the interpretations that lead to assertive decisions in profit and loss scenarios and how decisions are influenced by dark personality traits, which is still little debated in national studies in the business arena.

Still regarding the practical contribution, this study has an empirical application for people in business, as it discusses how human attitudes and behaviors within organizations are affected by personal factors, prompting a reflection on how psychosocial factors impact decisions. According to Moreno, Kida, and Smith (2002), many managerial decisions are made in an uncertain or risky environment. Managers use estimates for future projections, with decisions being reflected in accounting statements, as well as influencing the future decisions of various users of accounting information. Therefore, it becomes relevant to reflect on the impacts the narcissistic personality trait has on the influence of decisionmaking, as it raises the discussion about impulsiveness and risk propensity, to understand its implications in the business and Brazilian environment.

\section{Theoretical framework and development of hypotheses}

2.1 Decision-making under risk and uncertainty: comparison of decision theories

According to Baron (2008), "A decision is a choice of action - of what to do or not do. Decisions are made to achieve goals, and they are based on beliefs about what actions will 
RAUSP

56,1

achieve the goals" (p. 6). In the view of Simon (1963), a decision involves a three-phase process. A decision can be made based on complete or incomplete information. When incomplete, the risks and corresponding probabilities are not fully known, resulting in the making of decisions under uncertainty, which always carries risk (Baron, 2008).

The prediction and perception of uncertain events were first analyzed through two currents of research into decision-making. These currents culminated in the normative (or prescriptive) theory and the descriptive theory, providing scientific support to decisionmaking, and leading to the development of other theories, such as the PT and FTT, both with a psychological slant.

The normative theory concerns unlimited rationality, where the economic agent seeks to maximize his personal utility by choosing the best alternative in a context of full knowledge of all the possible states of the world. In this respect, Edwards (1954) presented three properties of the economic man: He is completely informed, infinitely sensitive and rational. The rational focus gives him the knowledge to make choices so as to maximize something. Mathematics made a major contribution to the normative current through game theory, as elaborated by Von Neumann and Morgenstern (1944), based on the notion that each individual chooses an alternative with a particular probability of maximizing utility, under conditions of risk and uncertainty.

Further analyzing this normative line of thinking, the studies of Friedman and Savage (1948) suggested that individuals' reactions to risk can be rationalized by means of analyzing utility, whereas Bernoulli (1954) proposed a new theory for measuring risk derived from utility.

Nevertheless, despite the relevance of these propositions, psychologists argued that this rational capacity to make decisions has limitations. Allais (1953) started the discussion about the rationality of the economic man by criticizing the previously postulated axioms and theories about risk. He added that experimental observations about the behavior of supposedly rational people indicated there is no general indicator that leads to an optimal situation that can be defined as a maximum expected value. Also in the 1950s, Simon postulated that human rationality is relative, limited by the lack of complete knowledge.

Simon (1955) compared the previous theories with real decision-making processes, finding discrepancies between the simplified models and reality, especially owing to the difficulty of comparing human intelligence with the capacity of computational processing.

2.1.1 Prospect theory. In 1972, Kahneman and Tversky (1972) published "Subjective probability: A judgment of representativeness," to discuss the heuristic called representativeness. In 1974, the authors expanded the scope of the study by including possible biases caused by heuristics in their paper "Judgment under uncertainty: heuristics and biases." And in 1979, they published the paper "Prospect theory: decision making under risk," to discuss how individuals react to situations of risk and uncertainty, with findings that contradicted the expected utility theory.

According to Kahneman and Tversky (1979), prospects can be understood as a type of contract that produces results through probabilities and bets; therefore, prospects generate the probability of uncertain and risky decisions. The authors conducted an experiment with 72 participants who were presented with choices about gain or loss, involving risk and uncertainty.

With respect to uncertainty, they observed that people opted for certain results as opposed to those considered unlikely. In the presence of this effect, agents are averse to losing and prefer something guaranteed, even with less value, to something uncertain. With respect to the certainty effect, the demonstrated propositions represent sure or uncertain gains, but there are no losses. With the reflection effect, however, losses were possible. In 
regard to this phenomenon, Kahneman and Tversky (1979) observed that in facing the possibility of a loss, individuals choose an uncertain option more than a confirmed loss, even if the latter is potentially lesser.

2.1.2 Fuzzy-trace theory. In the psychological line, Reyna and Brainerd (1995) experimented, based on the PT, if decision-makers process numerical information and if this is necessary to produce decisions. Situations of forced choice include the ability to differentiate between options; these options can influence the level of representation, especially when quantitative ambiguities exist and the assimilation of these ambiguities is not identical. The authors argued that reasoning and memory interfere in judgment and decision-making.

Reyna and Brainerd (1995) also contended that memory is represented independently by two systems: the literal (verbatim) and the essence (gist). These systems differ by the content and the precision of details. Gist memory is composed of diffuse representations that incorporate the meaning of an experience, such as affective, cultural and educational aspects, and other factors that interfere with the interpretation and inferences about facts. It is a broader, more robust and lasting memory but only stores unspecific information about the event. In its turn, verbatim memory is formed by precise representations that include details, but these are more susceptible to forgetfulness and to interference, making them inaccessible more quickly than gist memories (Reyna, Lloyd \& Brainerd, 2003).

This conception, emerging from various experiments, gave rise to the FTT, which involves a dual model of independence of memory and reasoning (Reyna \& Brainerd, 1991). In memory tests, participants are more likely to count on verbatim representations immediately after the original information is presented but switch to gist memory with the passage of time (Brainerd \& Reyna, 2002). The representations of the gist are diffuse and less precise than verbatim representations. People can use verbatim or gist representations to resolve problems of reasoning (although they mainly rely on gist). In this vein, numeric information is not necessary, nor is it sufficient to produce phenomena of decision framing (Reyna \& Brainerd, 1995).

Therefore, Reyna and Brainerd (1995) postulated that in the FTT, the processes of reasoning unfold in parallel instead of in a series, often operating on the most intimate sense of ideas (the gist of the problem), and are imprecise or qualitative, rather than precise. This is affirmed by traditional approaches that model reasoning in orderly steps (e.g. premises are first understood and then integrated to reach conclusions), with precision being considered a mark of good reasoning.

2.1.3 Prospect theory versus fuzzy-trace theory. According to Kuhberger and Tanner (2010), in recent decades there has been considerable interest in investigating how framing decision problems affects preferences. They reported how the framing effect (frame) involving the presentation of different but equivalent descriptions of a problem of choice can lead to different orders of preference.

A special category of framing effect arises in risky choice tasks with the famous Asian disease problem (Tversky \& Kahneman, 1981). The experiments involving this problem indicated that the majority of participants prefer the sure option when the options are positively framed but prefer the risky option when the options are negatively framed. When Reyna and Brainerd (1991) applied the problem of Tversky and Kahneman (1981) to a group of subjects, the typical result was that people chose the sure option in the context of gains and the risky option in the context of losses. The authors also produced experimental evidence challenging the traditional claim that the presence of numbers in the discussion of the problem is essential for these effects. They simply removed all the numbers from the standard problems and replaced them with vague statements such as "some people." The 
RAUSP

56,1

framing effects were not only still noted; they were greater in magnitude when the numbers were absent than when they were present (Reyna \& Brainerd, 1995).

Therefore, numerical information is not only unnecessary to detect these effects but also tends to mask the effects instead of amplifying them. More generally, this non-numerical framing effect demonstrated that crude qualitative distinctions are sufficient to produce the pattern of preferences.

Kuhberger and Tanner (2010) asserted that the PT, on the one hand, represents the traditional approach, proposing a formal model to evaluate and combine probabilities and results, whereas the FTT involves a cognitive process model where information is intuitively processed in a simplified manner. Their study of the theories aimed to identify the difference between the two approaches.

In light of the described studies, we formulated the following hypothesis:

H1. A significant difference exists between the decisions made based on the prospect and fuzzy-trace theories.

We based $H 1$ on the results presented by Kühberger and Tanner (2010); Reyna and Brainerd (1991, 1995); and Tversky and Kahneman (1981). These decision theories, especially the PT and FTT, are foundations for studies of personality traits, as discussed in Section 2.2.

\subsection{Narcissism}

Narcissism is a personality trait with characteristics of egocentrism, superiority, exhibitionism, authority, a sense of entitlement, self-sufficiency, vanity and exploitation of others (Raskin \& Terry, 1988). The name arises from the legend of Narcissus, a figure of Greek mythology who was so infatuated with himself that he fell in love with his own image in a pool of water and died because of the impossibility of consummating this love. Freud (1914/2010) referred to narcissists as people who look at themselves and who touch and caress themselves for sexual pleasure until they reach full satisfaction from these acts.

The original studies examined the clinical character of this personality trait, considering it to be a personality disorder. However, psychologists Raskin and Hall (1979), after various experiments, developed a personality measurement instrument, including the possibility of nonpathological manifestations, called the narcissistic personality inventory (NPI), still widely used by researchers in various fields of knowledge as an instrument to measure narcissistic traits in individuals in business settings (Majors, 2016; Dworkis, 2013).

Those who exhibit narcissistic traits are vain, sensitive to criticism, self-sufficient, egotistic, omnipotent and feel they have the right to exploit others owing to their superiority (Raskin \& Terry, 1988). In the organizational environment, white-collar crimes are related to individuals with strong narcissism, especially because their desire to be better than others leads to self-justification for committing fraud to reach personal objectives (Blickle, Schlegel, Fassbender \& Klein, 2006).

2.2.1 Previous studies: personality traits and prospect and fuzzy-trace theories. Studies analyze the relationship between decision-making in conditions of risk and personality or personality traits, in light of the PT and FTT.

Lauriola and Levin (2001) examined the relationships between personality traits of the Big Five (extroversion, affability, conscientiousness, neuroticism, openness to experience) and decision-making under risk, through the lens of PT. The applied experimental task contained trials in which individuals could make gains and trials in which individuals could avoid a loss. The effects of personality traits differed in terms of gains and losses. Personality factors predicted risk-taking mainly when the scenario was one of gains. The 
high scores of the trait openness to experience were associated with greater risk-taking, whereas high scores of neuroticism were associated with less risk-taking.

Along the same lines, Soane and Chmiel (2005) investigated, among other themes, the relationship between decision-making under conditions of risk and personality traits of the five factors. The authors realized that the most aware participants demonstrated an aversion to risk. The unconscious, on the other hand, are prone to prefer risk in decisionmaking.

Weller and Thulin (2012) investigated the HEXACO personality traits (especially the honesty-humility dimension and risk preferences), when the decision is presented as a potential gain or loss. The results showed that the honesty-humility dimension is associated with greater risk for both scenarios. Emotivity was associated with less risk in both scenarios, whereas low consciousness was only associated with taking risk to obtain gains.

When considering the FTT to support the investigation, Brunot \& Brunot (2017) aimed to identify HEXACO personality traits in individuals who process intuitive risk judgments. The results indicated differences in responses for the essence and literal systems, demonstrating that risk-taking is related to the honesty-humility and impulsiveness traits.

As for the studies that discuss the narcissistic personality trait related to decisionmaking, the results show that individuals with high traits of narcissism demonstrate impulsiveness and overconfidence in their knowledge and performance by agreeing with risky bets that could result in victory and success, even though they know that the consequences can be harmful to the company (Lakey, Rose, W. K Campbell, \& Goodie, 2008; W. K Campbell, Goodie, \& Foster; 2004; WK, Campbell, Hoffman, SM Campbell, \& Marchisio, 2011), because the courage for risky decisions comes from the need for praise when business performance is higher than expected (Chatterjee \& Hambrick, 2011).

Meisel et al. (2015) conducted a study of narcissism among American and Chinese college students, involving decisions under conditions of risk and excessive confidence. The Chinese students obtained higher self-confidence and risk exposure scores, whereas the American students accrued higher narcissism averages. Buelow and Brunell (2014) investigated the role of the narcissistic traits of grandiosity, entitlement and exploitation in risky behaviors. A total of 630 undergraduate college students participated, and higher levels of narcissistic grandiosity were associated with risky behavior.

Buyl, Boone, and Wade (2017) investigated how the narcissism of Chief Executive Officers (CEOs) affects risky decision-making in their companies in light of the monitoring of corporate governance practices. The authors found that narcissistic traits among CEOs have a positive effect on banks' levels of risk, especially regarding compensation policies that encourage taking risks.

Foster, Shenesey, and Goff (2009) investigated what motivates narcissistic individuals to engage in risky behaviors. The results indicated that the narcissists make risky decisions fueled by heightened perceptions of the benefits of risky behaviors. In other words, narcissists, because of their excessive anxiety, more frequently adopt potentially problematic behaviors, such as assuming risks.

Yang et al. (2018) applied a monetary gambling task to individuals with high and low levels of narcissism, involving choosing between a high-risk and low-risk option, and measured their reactions by recording an electroencephalogram. The results indicated that the subjects with high and low narcissism differed in the high-risk condition but not in the low-risk condition. At the behavioral level, those with high narcissism made riskier decisions.

Based on the studies described above, we formulated the following hypothesis:

H2. Individuals with high narcissism scores are more likely to make risky decisions. 
RAUSP

56,1

H2 is supported by the studies of Yang et al. (2018); Buyl, Boone, and Wade (2017); Meisel et al. (2015), Campbell et al. (2011); Foster et al. (2009), Lakey et al. (2008); and Campbell et al. (2004). Moreover, as stated by Carré and Jones (2016) in evaluating the FTT and Machiavellianism (one of the traits that form the dark triad cluster, along with narcissism and psychopathy), analytical reasoning is influenced by personality traits that affect decision-making under conditions of risk.

\section{6}

\section{Methodology}

\subsection{Approach, data collection technique and research sample}

We adopted a theoretical-empirical approach, gathering data through a self-reported questionnaire composed of three parts. Part I asked questions related to the demographic profile. Part II had 40 statements from the NPI of Raskin and Terry (1988), validated for Brazil by Magalhães and Koller (1994), to measure the following traits: Authority, selfsufficiency, superiority, exhibitionism, exploitation, vanity and entitlement. Part III was comprised of a simulation game adapted from the studies of Tversky and Kahneman (1981); Reyna and Brainerd (1991, 1995); and Kuhberger and Tanner (2010), to compare decisions under conditions of risk and uncertainty, based on the PT and FTT. We adapted the scales to address our research problem because they have been examined in previous Brazilian studies (Kimura, Basso, \& Krauter, 2006; Yoshinaga \& Carvalho, 2014).

We formulated and adapted the simulation game for application in a business setting as described in the following:

You are the CEO of a large multinational company with 1,000 units around the world. At a meeting with the general manager of each unit, it was reported that 600 of these companies are in dire financial straits and might have to be closed. The discussion with your colleagues allowed for the formulation of four programs (1,2,3 and 4) to try to save these companies. Therefore, decide which options you would choose from the pairs below:

\begin{tabular}{lllc}
\hline Scenarios & Options & \multicolumn{2}{c}{ Alternative } \\
\hline 1 & $\begin{array}{l}\text { Alternative A - If Program A is adopted, 200 companies will be saved. } \\
\text { Alternative B - If Program B is adopted, there is a 1/3 probability that 600 will } \\
\text { be saved and a 2/3 probability that no companies will be saved. }\end{array}$ & A & B \\
2 & $\begin{array}{l}\text { Alternative A - If Program C is adopted, 400 companies will be closed. } \\
\text { Alternative B - If Program D is adopted, there is a 1/3 probability that no } \\
\text { companies will be closed and a 2/3 probability that 600 companies will be } \\
\text { closed. }\end{array}$ & A & B \\
& $\begin{array}{l}\text { Alternative A - If Program A is adopted, some companies will be saved. } \\
\text { Alternative B - If Program B is adopted, some companies will be saved or no } \\
\text { companies will be saved. }\end{array}$ & A & B \\
& $\begin{array}{l}\text { Alternative A - If Program C is adopted, some companies will be closed. } \\
\text { Alternative B - If Program D is adopted, some companies will be closed or no } \\
\text { companies will be closed. }\end{array}$ & A & B \\
4 & & \\
\hline
\end{tabular}

It is noteworthy that the narcissistic personality measurement instrument is not a psychological test, and is not intended for clinical diagnosis, but rather for the observation of psychosocial phenomena.

Our sample totaled 210 academics from the business arena (accountants and administrators), who hold or have held management positions, among the 700 participants of 
the scientific conference, in December 2018, of the Accounting and Actuarial Department of the Faculty of Economics, Administration and Accounting at the University of São Paulo (FEA/ USP), who provided valid e-mails and met the selection criteria for the study. We chose the sample based on accessibility and in a nonprobabilistic way, which did not allow us to generalize the results but did allow us to observe the phenomena related to the study's purpose.

Narcissism, risk and uncertainties

\subsection{Research variables, parameterization and statistical analysis}

Narcissism is the independent variable, as it impacts decision-making, which is the dependent variable. The research design is illustrated in Figure 1:

The NPI (Raskin \&Terry, 1988) was parameterized by following the criteria of the original study, with 40 statements indicative of narcissistic traits (each assigned 1 point) and nonnarcissistic traits (0 points). For example, Statement 1: A - "Modesty is not my strong suit" (1 point, narcissistic trait) and B - "I'm essentially a modest person" (0 points, non-narcissistic trait). The maximum score on the instrument is 40 points, if the participant chooses all the statements denoting narcissistic traits. The sum of the points is a quantitative variable.

With parameterization of the low and high levels of narcissism, we divided the group into two ranges, such that a score below the median was considered to denote low narcissism and a score above the median, high narcissism. For this qualitative variable, we assigned a score of 1 for low level and 2 for high level. Yang et al. (2018) and Dworkis (2013) adopted a similar procedure.

To parameterize decision-making, we adopted the following criterion, both for the positive and negative scenarios, and for the two methods applied according to the theories (PT and FTT): 0 (zero) for decisions under certainty and 1 (one) for risky decisions. Kuhberger and Tanner (2010) used this procedure.

Regarding the statistical approach, we took the following into consideration: descriptive statistics (frequency, mean, standard deviation, maximum and minimum values), the MannWhitney and Kruskal-Wallis, owing to the nature of the variables and correlation and logistic regression. We used these techniques to test $H 1$ and $H 2$ of this study.

\section{Analysis of the results}

\subsection{Profile of the participants}

Of the 210 respondents, $51.9 \%$ were women and $36.7 \%$ were between the ages of 26 and 35 , $68.1 \%$ held postgraduate degrees in the area of business and $69.5 \%$ had between five and ten years of professional experience in the management area.

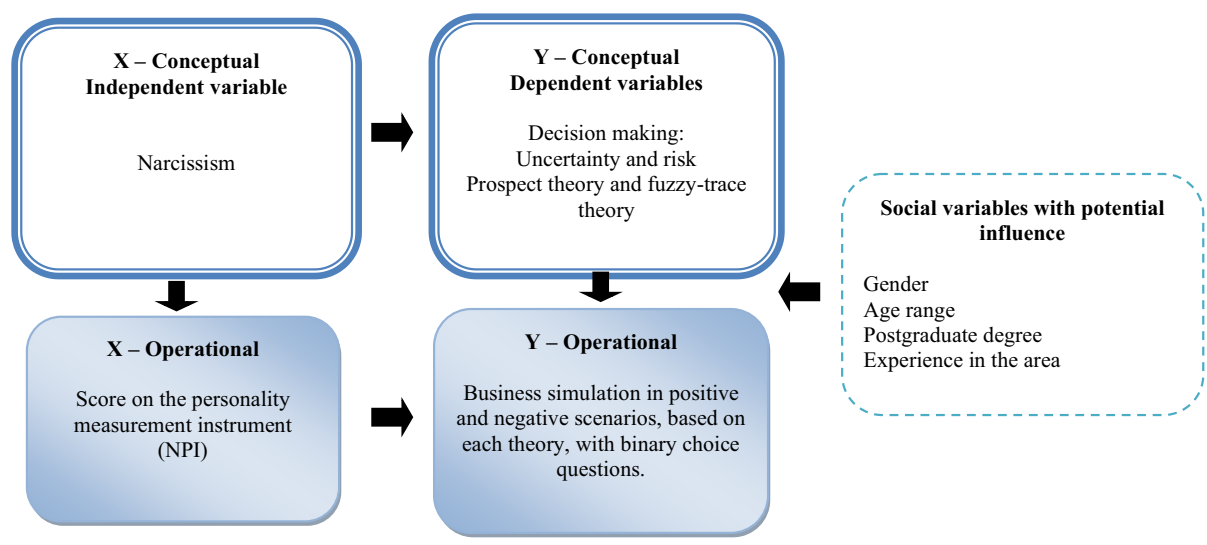

Figure 1. Narcissism and decision-making 
RAUSP

56,1

138

Table 1.

Descriptive statistics
With respect to the narcissism scores, the highest was 29 (out of a possible 40 points) and the lowest was 2. The mean was $\bar{x}=13.24$. We show these data in Table 1. Comparing Brazilian studies that adopted the same data collection instrument, the investigation by D'Souza, Oliveira et al. (2019) found an average slightly above $\bar{x}=13.68$ with business students. Lima et al. (2018) found a lower mean, $\bar{x}=12.62$, with accounting students. This result allows for the inference that business students are more prone to narcissistic characteristics than academic business professionals, with no intention of generalizing the results.

Other Brazilian investigations included narcissism as a topic of study, but used other research instruments, with a different score to verify the disposition for the dark trait. D'Souza, Lima et al. (2019) and D'Souza and Lima (2015) used the short dark triad (SD3; Jones and Paulhus, 2014) to collect nine Likert-type statements (1-5 points) regarding disposition to narcissistic traits. The authors found mean $\bar{x}=2.8$ with managers and $\bar{x}=$ 3.01 with Master in Business Administration (MBA) students, respectively. In a different vein, Góis (2017) used the SD3 (Jones and Paulhus, 2014) but used the Likert scale (1-10 points) and found an average $\bar{x}=4.81$ with MBA students, proportionally smaller than the ones in previous studies. D'Souza and Lima (2019) - using the same instrument but with the Likert scale (1-7) points - found $\bar{x}=3.49$ with accounting students.

The results are proportional but with a greater narcissistic disposition for MBA students. The postgraduate academic environment can be a sign of strong competitiveness and vanity that encourages students to feel self-sufficient and superior, implying a rush to achieve good results, such as publications in qualified journals.

When analyzing the disposition of academics in the business arena, by level (low, high) of narcissistic traits, we observed a well-balanced score, although the lowest traits proved to be the majority $(51 \%)$. When checking in detail the assertions of the applied NPI instrument, we observed that the respondents showed stronger agreement with the following statements: "I am a born leader" (77.6\%); "When I feel competent, I take the decision" (64.8\%); "I see myself as a good leader" (61.4\%); "I have a natural talent for influencing people" (61\%); "I will be a success" (55.2\%); and "I can decipher people as if they were a book" (55.2\%). The analysis of these results points to a greater disposition to self-sufficiency characteristics, followed by authority, exploitation and superiority (Table 2). This implies that respondents feel confident with the power to decide and delegate tasks that will be obeyed by subordinates. This confidence, on the one hand, can benefit companies, as a

\begin{tabular}{ccccccc}
\hline & Observations & Mean & Standard deviation & Maximum & Minimum & Variance \\
\hline Narcissism score & 210 & 13.24 & 5.779 & 29 & 2 & 33.398
\end{tabular}

Source: Research data

\begin{tabular}{lcr}
\hline Levels & $N$ & Narcissism \\
& \multicolumn{1}{c}{} & $(\%)$ \\
\hline Low & 107 & 51 \\
High & 103 & 49 \\
Total & 210 & 100 \\
Source: Research data & & \\
\hline
\end{tabular}

Table 2.

Frequencies

Source: Research data 
leader who shows confidence leads a team to achieve goals. However, if confidence and authority are in excess, they prevent participatory leadership and the sharing of ideas with subordinates who carry out operational activities and who closely know the potential and problems of each area of the company.

With respect to decision-making, for both PT and FTT, in the positive scenario, the leading choice was certainty $(68.8 \%$ and $62.9 \%$, respectively), whereas in the negative scenario the most frequent choice was to assume risk $(69.0 \%$ and $61.9 \%$, respectively). These results are convergent with the findings of Tversky and Kahneman (1981); Kimura, Basso, and Krauter (2006); Yoshinaga and Carvalho (2014); Reyna and Brainerd (1991, 1995); and Kuhberger \& Tanner (2010). This indicates that in positive scenarios, when the participants were faced with the possibility that some of the companies would survive, they tended to choose the option with a safe outcome, whereas in negative scenarios, with the possibility that some companies would fail, they were inclined to assume risk, trying to save more companies than those in the business simulation (Table 3).

Regarding the relationship and significance of the variables, narcissism was associated with all the decisions, in the methodologies of both the PT and FTT, although with different results. In Decision I, of the positive scenario, considering the PT methodology, the correlation was negative $(r=-0.636$, with $p<0.01)$, denoting that an increase in narcissistic traits of the academics was associated with lower propensity to choose the decision with the sure outcome. The correlation was also negative $(r=-0.753$, with $p<0.01)$ with the FTT methodology, indicating that, in positive scenarios, individuals with strong narcissism prefer risk.

In the negative scenario, regarding Decision II and considering the PT method, the correlation was positive $(r=0.694$, with $p<0.01)$, denoting that an increase of narcissistic traits of the academics increased their propensity to make a risky decision. The correlation was also positive $(r=0.760$, with $p<0.01)$ in the FTT methodology, and the magnitude was greater when the numbers were absent than when they were present, as also found by Reyna and Brainerd (1995).

The results of this study corroborate the narcissistic characteristics of risk-taking, competitiveness, need for power and glory and impulsiveness. Narcissists bet, even in situations where gains are sure, owing to excess of confidence, search for sensations, arrogance and pursuit of constant attention. Furthermore, our findings converge with those of Meisel et al. (2015), who observed that Chinese students with strong narcissism presented higher self-confidence and exposure to risk scores. Along the same lines, Foster et al. (2009) also perceived that narcissists tend to make risky decisions, expecting possible benefits and gains stemming from these risks. These findings confirm $\mathrm{H} 2 \mathrm{of}$ this study.

\begin{tabular}{|c|c|c|c|c|c|c|c|}
\hline Prospect theory & Choices & $N$ & $(\%)$ & Fuzzy-trace theory & Choices & $N$ & $(\%)$ \\
\hline $\begin{array}{l}\text { Decision I } \\
\text { Positive scenario }\end{array}$ & Alternative A & 144 & 68.8 & $\begin{array}{l}\text { Decision I } \\
\text { Positive scenario }\end{array}$ & Alternative A & 132 & 62.9 \\
\hline & Alternative B & 66 & 31.4 & & Alternative B & 78 & 37.1 \\
\hline Total & & 210 & 100 & Total & & 210 & 100 \\
\hline $\begin{array}{l}\text { Decision II } \\
\text { Negative scenario }\end{array}$ & Alternative A & 65 & 31.0 & $\begin{array}{l}\text { Decision II } \\
\text { Negative scenario }\end{array}$ & Alternative A & 80 & 38.1 \\
\hline Total & Alternative B & $\begin{array}{l}145 \\
210\end{array}$ & $\begin{array}{c}69.0 \\
100\end{array}$ & Total & Alternative B & $\begin{array}{l}130 \\
210\end{array}$ & $\begin{array}{c}61.9 \\
100\end{array}$ \\
\hline
\end{tabular}

Narcissism, risk and uncertainties

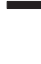


RAUSP

56,1

140

In analyzing the other variables in the study, academics with a postgraduate level in business associated themselves with narcissistic traits. Given this result, we can infer that the degree leads the professional to vanity and the need to always be highlighted in academic and work environments (Table 4).

To confirm the difference in decision-making in the positive and negative scenarios, we performed analysis of variance. As shown in Tables 5 and 6, both in PT and FTT, Decision I and Decision II presented results of $F(1,209)=359.189, p<0.001$, and $F(1,209)=468.844$, $p<0.001$, respectively. These results suggest the existence of a difference in decisions between individuals according to the PT and FTT. We can thus infer that the participants differed in their choices when replacing numbers (PT) with words like "some" or "no," as used by the FTT.

According to the FTT, individuals make choices between certainty and risk based more on simpler and less precise representations than on numerical information. We can divide these essential representations according to the context they were presented in to individuals, as done by Brainerd \& Reyna (2002). In the gain context, options are reduced to choosing between (a) saving some companies or (b) the chance of saving some companies or not saving any companies at all. The probabilities associated with these two options are again reduced to a dichotomous category in which an option is (a) certain or (b) uncertain. When asked to choose between these two options, it is reasonable to expect individuals to opt for (a) saving the companies or (b) the chance of saving the companies.

Likewise, in every loss context, the options are reduced to (c) some companies will fail, or (d) some companies might fail or none will fail. Here also it is understandable that people choose the option in which no company will fail. Even though this option (d) is uncertain, it is seen as substantially better than the alternative (c) where it is certain that some companies will fail. Although these suppositions are diametrically opposed, both models lead to identical predictions in the classic framing effect (Kuhberger \& Tanner, 2010). These findings support $H 2$ of this study.

Regarding the differences between decision-making and narcissistic traits, Table 7 shows that the academics with stronger narcissism made different decisions in each gain and loss scenario than did those weaker in narcissism, based on the two theories investigated. As stated by Campbell et al. (2011), narcissists make riskier choices out of a desire for victory and praise, even when they recognize that the future consequences can be harmful both for individuals and the group. Jones (2014) had already found that in games of

\begin{tabular}{|c|c|c|c|c|c|c|c|c|c|}
\hline & Narc & $\begin{array}{l}\text { D I } \\
\text { PT }\end{array}$ & $\begin{array}{l}\text { D II } \\
\text { PT }\end{array}$ & $\begin{array}{c}\text { D I } \\
\text { FTT }\end{array}$ & $\begin{array}{l}\text { D II } \\
\text { FTT }\end{array}$ & Sex & Age range & Postgrad degree & Exp \\
\hline Narcissism & 1 & & & & & & & & \\
\hline D IPT & $-0.636\left(^{* *}\right)$ & 1 & & & & & & & \\
\hline D II PT & $0.694\left(^{* *}\right)$ & $-0.834\left(^{* *}\right)$ & 1 & & & & & & \\
\hline D IFTT & $\left.-0.753{ }^{(* *}\right)$ & 0.796 (**) $^{* *}$ & $\left.-0.850^{* * *}\right)$ & 1 & & & & & \\
\hline D II FTT & $0.760\left(^{(* *}\right)$ & $-0.779\left(^{* *}\right)$ & $\left.0.8322^{* *}\right)$ & $-0.980\left(^{* *}\right)$ & 1 & & & & \\
\hline Sex & -0.10 & -0.015 & 0.67 & -0.050 & 0.29 & & & & \\
\hline Age range & -0.41 & -0.043 & 0.113 & -0.052 & 0.016 & $\left.0.2655^{* *}\right)$ & 1 & & \\
\hline Postgrad & $-0.135(\stackrel{*}{)}$ & 0.045 & -0.016 & 0.040 & -0.032 & 0.254 (**) $^{* *}$ & $\left.0.2544^{* *}\right)$ & 1 & \\
\hline Experience & -0.10 & -0.78 & $0.121\left({ }^{*}\right)$ & -0.82 & 0.042 & $0.790\left(^{* *}\right)$ & $\left.0.1799^{(* *)}\right)$ & $0.179\left(^{* * *}\right)$ & 1 \\
\hline
\end{tabular}

Table 4. Correlation
Notes: Narc: narcissism; Postgrad: postgraduate degree; Exp: experience. Note $2:{ }^{* *} p<0.01 ;{ }^{*} p<0.05$ Source: Research data 
chance, people with strong narcissism lose more money by taking greater risks than other individuals who exhibit dark traits, such as psychopaths. These findings also support $H 2$.

With respect to the other variables with potential influence, such as sex, age range, postgraduate degree and time of experience, the findings showed no difference between individuals with high and low narcissism.

To confirm the previous results and verify the probability of the event occurring, we applied logistic regression, given the dichotomous nature of the variables that represent the four decision scenarios, deemed to be dependent variables, and also because it is a more robust technique for the marginal analysis of the interactive variable between narcissism, the independent variable, and postgraduate degree, the control variable (Narc*PosGrad), chosen for this test owing to the correlation between the two variables.

The results showed by means of the chi-square test the significance of the model for the four scenarios ( $\operatorname{sig}=0.000$ ), which allows us to infer that the inserted variables provide an opportunity for the interpretation that the model is able to accurately predict the investigation. According to Table 8, the model is adequate (-2LL), less than 1 for the four

\begin{tabular}{lcrccc}
\hline & Sum of squares & \multicolumn{1}{c}{ df } & Mean square & $F$ & Sig. \\
\hline Between groups & 31.049 & 1 & 31.049 & 359.189 & $0.000^{*}$ \\
Within groups & 17.980 & 208 & 0.086 & & \\
Total & 49.029 & 209 & & &
\end{tabular}

Note: ${ }^{*} p<0.05$

Source: Research data
Narcissism, risk and uncertainties

\begin{tabular}{lcccrr}
\hline & Sum of squares & df & Mean square & $F$ & Sig. \\
\hline Between groups & 34.305 & 1 & 34.305 & 468.844 & $0.000^{*}$ \\
Within groups & 15.219 & 208 & 0.073 & & \\
Total & 49.524 & 209 & & &
\end{tabular}

Note: ${ }^{*} p<0.05$

Source: Research data

15.219
Table 6. ANOVA: difference between Decision II of the PT and Decision II of the FTT

\begin{tabular}{llcl}
\hline & & Narcissism & \\
Dependent variable & Test & Sig & Decision \\
\hline Decision I PT (positive scenario) & Mann-Whitney & $0.000^{*}$ & Rejected \\
Decision II PT (negative scenario) & Kruskal-Wallis & $0.000^{*}$ & Rejected \\
Decision I FTT (positive scenario) & Mann-Whitney & $0.000^{*}$ & Rejected \\
Decision II FTT (negative scenario) & Mann-Whitney & $0.00\left(^{*}\right)$ & Rejected \\
Sex & Mann-Whitney & 0.876 & Not rejected \\
Age range & Kruskal-Wallis & 0.954 & Not rejected \\
Postgraduate degree & Mann-Whitney & 0.177 & Not rejected \\
Experience & Kruskal-Wallis & 0.910 & Not rejected
\end{tabular}

Note: ${ }^{*} p<0.05$

Source: Research data

Table 7.

Hypotheses tests 
RAUSP

56,1

\section{2}

Table 8.

Adjustment to the model scenarios. It appears that $10 \%, 12.3 \%, 12.9 \%$ and $13.4 \%$ of the probable variations of occurrence are explained by the variable (Narc*PosGrad). And the statistical model is able to explain $14.1 \%, 17.4 \%, 17.6 \%$ and $18.2 \%$, the variations registered in the decision scenarios based on PT and FTT, respectively.

These results confirm that FTT explains the phenomenon under study more intensely, as in the studies by Kuhberger and Tanner (2010) and Reyna and Brainerd (1991). Note that the simplest and most accurate language proposed by FTT can mitigate problems of interpretation and complexity observed in previous studies and can serve as a good reference for the application of the research with business and accounting students with little maturity and experience in decision-making.

Table 9 shows that the (Narc*PosGrad) variable was positive and significant for the four scenarios, showing that the positive variation contributes to the increase in the likelihood of respondents deciding on risk, both in the scenario of gain and loss. If (Narc*PosGrad) increases by 1 , the estimated logit increases by an average of $0.901,1.126,0.892$ and 1.124 , suggesting a positive relationship between risky decisions and narcissism.

These results converge with the findings of Lauriola and Levin (2001), who predicted that individuals open to experiences are more likely to take risks in gains scenarios. Along the same lines, Soane and Chmiel (2005) realized that less aware individuals prefer risk in decision-making. Weller and Thulin (2012) found that individuals with traits that refer to honesty-humility also sought greater risk for the scenarios of gain and loss.

\begin{tabular}{lcccc}
\hline Step 1 & $\begin{array}{c}\text { Decision I PT } \\
\text { (positive scenario) }\end{array}$ & $\begin{array}{c}\text { Decision II PT } \\
\text { (negative scenario) }\end{array}$ & $\begin{array}{c}\text { Decision I FTT } \\
\text { (positive scenario) }\end{array}$ & $\begin{array}{c}\text { Decision II FTT } \\
\text { (negative scenario) }\end{array}$ \\
\hline Likelihood (-2LL) & 239,221 & 232.187 & 248.165 & 248.868 \\
Cox and Snell R square & $10 \%$ & $12.3 \%$ & $12.9 \%$ & $13.4 \%$ \\
Nagelkerke R square & $14.1 \%$ & $17.4 \%$ & $17.6 \%$ & $18.2 \%$
\end{tabular}

Note: Estimation terminated at iteration number 4 because the parameter estimates changed by less than 0.001

Source: Research data
Table 9.

Logistic regression

\begin{tabular}{|c|c|c|c|c|c|c|}
\hline $\begin{array}{l}\text { Dependent } \\
\text { variable }\end{array}$ & Independent variable & Expected signal & $\begin{array}{l}\text { Found } \\
\text { signal }\end{array}$ & Coef. $B$ & $\begin{array}{l}\text { Coef. } \\
\operatorname{Exp}(\beta)\end{array}$ & $\begin{array}{c}\text { Wald test } \\
p \text {-value }\end{array}$ \\
\hline \multirow{8}{*}{$\begin{array}{l}\text { Decision I PT } \\
\text { (positive scenario) } \\
\text { Decision II PT } \\
\text { (negative scenario) } \\
\text { Decision I FTT } \\
\text { (positive scenario) } \\
\text { Decision II FTT } \\
\text { (negative scenario) }\end{array}$} & Narc*PosGrad & + & - & 0.104 & 0.901 & 0.000 \\
\hline & Constant & $+1-$ & + & 0.012 & 1.012 & 0.957 \\
\hline & Narc*PosGrad & + & + & 0.119 & 1.126 & 0.000 \\
\hline & Constant & $+1-$ & - & 0.083 & 0.920 & 0.709 \\
\hline & Narc*PosGrad & + & - & 0.115 & 0.892 & 0.000 \\
\hline & Constant & $+1-$ & + & 0.372 & 1.451 & 0.095 \\
\hline & Narc*PosGrad & + & + & 0.117 & 1.124 & 0.000 \\
\hline & Constant & $+1-$ & - & 0.435 & 0.647 & 0.052 \\
\hline
\end{tabular}

Notes: DI - Decision I; DII - Decision II; PT - prospect theory; FTT - fuzzy-traces theory; Narc*PosGrad: Narcissism*Postgraduate degree; Coef.: Coefficient; $p<0.05$

Source: Research data 
The results of these studies already show that personality traits influence risky interpretations and decisions. The concern is that the risky decisions of narcissistic managers can cause shortand long-term losses for investors and society. A risky decision without calculating the impact on results can have irreversible consequences for the business.

Figure 2 illustrates the comparison of the marginal means estimated for the variables narcissism and decisions in the gain and loss scenarios, indicating that the higher the level of narcissism, the greater the propensity to make risky decisions and the lower the propensity to choose the sure option, according to the two adopted methodologies.

It is worth discussing here the adverse behavior of the narcissistic individual who contradicts the results of previous studies on the application of the PT and FTT. While individuals without excessive narcissism prefer not to take a risk when there is a probability of sure gains, even if they do not reach $100 \%$ of the goal, the impulsiveness of narcissistic individuals impels them to seek the greatest possible gains, even if this compromises the financial and economic health of the company as a whole. The narcissistic manager seeks self-promotion, takes pleasure in risk and is comfortable with uncertain, risky decisions as a strategy, because if successful, they will be recognized as the manager of excellence who leveraged the company to achieve the best results, and consequently, will make the company more attractive in the market. Here, the vanity of recognition emerges, but also the selfishness and arrogance in decision-making that has negative consequences for all those interested in the business if the decision is not successful.

Based on the results, the statistical techniques validated both $H 1$ and $H 2$, consistent with the PT and FTT, indicating that subjective factors - such as personality traits - have an impact on attitudes, interpretations and decision-making.
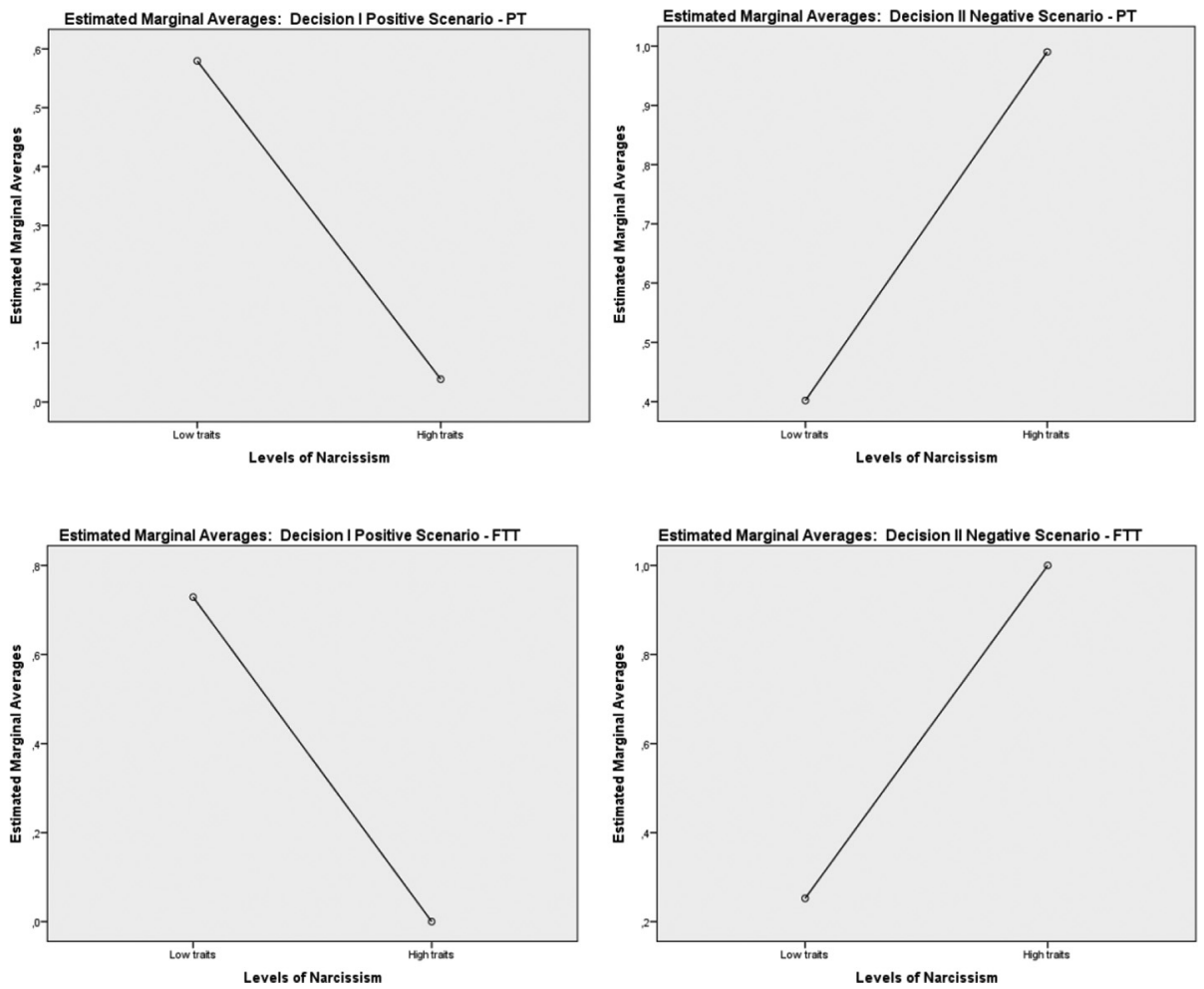

Figure 2.

Graph of the marginal means estimated for the levels of narcissism and decisions in the positive and negative scenarios in the DT andFTT 


\section{RAUSP}

56,1

\section{Conclusion}

People who have narcissistic traits tend to seek strong sensations and make risky decisions without concern for the long-run consequences. In analyzing the relationship between narcissistic traits and risky decisions, in light of the PT and FTT, this study conducted a survey among academics from the business arena.

The results indicated a lower propensity for narcissistic traits among the respondents, although many strongly agreed with the statements "I'm a born leader," "When I feel competent, I make the decision," "I see myself as a good leader," "I have a natural talent for influencing people," "I'm a success" and "I can read people like a book." These results suggest greater propensity for the traits of self-sufficiency, vanity, authority, exploitation and superiority, marks of individuals with strong narcissism.

While these traits can promote success in business activities, they can also be destructive when present in excess. If the influence over others that narcissists believe to have is used to commit illicit acts and organizational fraud, so that they remain in power as the leaders that achieve the best outcomes, the short- and long-term consequences stemming from their decisions can give rise to problems of business imbalance.

The results also showed a significant difference between the decisions according to the PT and FTT. The replacement of numerical values used in the PT with the words "some" versus "no" in the FTT contrasts with the effects of the PT, although the two theories make similar predictions about the classic framing effect. While the null effect is irrelevant for the PT, it is crucial for the FTT, given that individuals tend to prefer simpler alternatives that involve the gist of the decision, because people only keep unspecific information about events. We also note that the results using the FTT are greater in magnitude and can better explain the phenomenon under study.

In this sense, these findings led us to the answer to the research problem and to achieving our study objective. The hypotheses were not rejected, allowing for the discussion and expansion of studies on the theme. We expect that the findings will spur academics in the business arena to realize that risky decisions can compromise financial health and well-being in the business environment.

Our study contends, therefore, that the proposal of this scientific debate can be fruitful, starting from the idea that organizations become reflections of their main executives, considering that decision-making comprises complex choices and is deeply influenced by personality traits. Furthermore, the interdisciplinary deepening of this theme, in light of the PT and FTT, can improve the understanding of the dynamics of decision-making in organizations, although we recognize the limitation of results owing to respondents' biases in describing their own characteristics and behavior, given the application of a self-reported personality questionnaire.

Thus, it is suggested that future research expand the scope of the work, applying it to business professionals in the market and including the other personality traits that make up the dark triad cluster (Machiavellianism and psychopathy) and then comparing the results.

\section{References}

Allais, M. (1953). L'extension des theories de l'equilibre economique general et du rendement social au cas du risque. Econometrica, 21(2), 269-290. doi: https://doi.org/10.2307/1905539.

Amernic, J. H., \& Craig, R. J. (2010). Accounting as a facilitator of extreme narcissism. Journal of Business Ethics, 96(1), 79-93. doi: https://doi.org/10.1007/s10551-010-0450-0.

Avelino, B. C., \& de Lima, G. A. S. F. (2017). Narcisismo e desonestidade acadêmica. Revista Universo Contábil, 13(3), 70-89. doi: https://doi.org/10.4270/ruc.2017319.

Baron, J. (2008). Thinking and deciding, 4th ed., New York, NY: Cambridge University. 
Bernoulli, D. (1954). Exposition of a new theory on the measurement of risk. Econometrica, 22(1), 23-36. doi: https://doi.org/10.2307/1909829.

Blickle, G., Schlegel, A., Fassbender, P., \& Klein, U. (2006). Some personality correlates of business white-collar crime. Applied Psychology, 55(2), 220-233. doi: https://doi.org/ 10.1111/j.1464-0597.2006.00226.x.

Braga, R. (2015). Ganhos e perdas em investimentos: Um estudo experimental sobre personalidades à luz da teoria do prospecto e do efeito disposição. Doctoral dissertation, Universidade de São Paulo.

Brainerd, C. J., \& Reyna, V. F. (2002). Fuzzy-trace theory and false memory. Current Directions in Psychological Science, 11(5), 164-169. October). doi: https://doi.org/10.1111/1467-8721.00192.

Brunot, A., \& Brunot, A. N. (2017). Individual differences in intuitive risk judgments. Thesis. Psychology, and Business Administration. EUA: Oregon State University.

Buelow, M. T., \& Brunell, A. B. (2014). Facets of grandiose narcissism predict involvement in healthrisk behaviors. Personality and Individual Differences, 69, 193-198. doi: https://doi.org/10.1016/j. paid.2014.05.031.

Buyl, T., Boone, C., \& Wade, J. B. (2017). CEO narcissism, risk-taking, and resilience: An empirical analysis in US commercial banks. Journal of Management, 45(4), 1372-1400. doi: https://doi.org/ $10.1177 / 0149206317699521$.

Campbell, W. K., Goodie, A. S., \& Foster, J. D. (2004). Narcissism, confidence, and risk attitude. Journal of Behavioral Decision Making, 17(4), 297-311. doi: https://doi.org/10.1002/bdm.475.

Campbell, W. K., Hoffman, B. J., Campbell, S. M., \& Marchisio, G. (2011). Narcissism in organizational contexts. Human Resource Management Review, 21(4), 268-284.

Carre, J. R., \& Jones, D. N. (2017). Decision making, morality, and Machiavellianism: The role of dispositional traits in gist extraction. Review of General Psychology, 21(1), 23 doi: https://doi.org/ 10.1037/gpr0000093.

Chatterjee, A., \& Hambrick, D. C. (2011). Executive personality, capability cues, and risk taking: How narcissistic ceos react to their successes and stumbles. Administrative Science Quarterly, 56(2), 202-237. doi: https://doi.org/10.1177/0001839211427534.

D’Souza, M. F., \& Lima, G. A. S. F. (2019). Um olhar sobre os traços do dark triad e os valores culturais de estudantes de contabilidade. Advances in Scientific and Applied Accounting, 1(1), 161-183.

D’Souza, M. F., Lima, G. A. S. F. D., Jones, D. N., \& Carre, J. R. (2019). Eu ganho, a empresa ganha ou ganhamos juntos? Traços moderados do dark triad e a maximização de lucros. Revista Contabilidade \& Finanças, 30(79), 123-138. doi: https://doi.org/10.1590/1808-057x201806020.

D’Souza, M. F., Oliveira, M. L. S., Almeida, J. S. C., \& Natividade, D. S. (2019). EU posso, você pode, EU posso mais. Revista De Educação E Pesquisa Em Contabilidade (Repec)), 13(2) Retrieved from: https://oi.org/10.17524/repec.v13i2.2103 doi: https://doi.org/10.17524/repec.v13i2.2103.

D’Souza, M. F., \& de Lima, G. A. S. F. (2018). Escolha de carreira: O dark triad revela interesses de estudantes de contabilidade. Revista de Contabilidade e Organizações, 12, e151837-e151837. doi: https://doi.org/10.11606/issn.1982-6486.rco.2018.151837.

D’Souza, M., Aragão, I. R., \& De Luca, M. (2018). Análise da ocorrência de maquiavelismo e narcisismo no discurso nos relatórios administrativos de empresas envolvidas em escândalos financeiros. Revista De Educação E Pesquisa Em Contabilidade (REPeC), 12(3).

D’Souza, M. F. (2016). Manobras financeiras e o dark triad: O despertar do lado sombrio na gestão. Tese de Doutorado. São Paulo, SP: Universidade de São Paulo.

Dworkis, K. (2013). The interactive effects of incentive threshold and narcissism on managerial decision-making. Doctoral dissertation, Los Angeles, CA: University of Southern California, Retrieved from: http://digitallibrary.usc.edu/cdm/ref/collection/p15799coll3/id/129532

Edwards, W. (1954). The theory of decision making. Psychological Bulletin, 51(4), 380-417. doi: https:// doi.org/10.1037/h0053870. 
RAUSP

56,1

Foster, J. D., Shenesey, J. W., \& Goff, J. S. (2009). Why do narcissists take more risks? Testing the roles of perceived risks and benefits of risky behaviors. Personality and Individual Differences, 47(8), 885-889. doi: https://doi.org/10.1016/j.paid.2009.07.008.

Freud, S. (1914). S. Freud, (Ed.), pp. 12. São PauloCompanhia das Letras: Introdução ao narcisismo, InObras completas. Tradução de Paulo César de Souzap.

Friedman, M., \& Savage, L. J. (1948). The utility analysis of choices involving risk. Journal of Political Economy, 56(4), 279-304. doi: https://doi.org/10.1086/256692.

Góis, A. D. (2017). The dark tetrad of personality and the accounting information quality: The moderating effect of corporate reputation. Tese de Doutorado, Faculdade de Economia, Administração e Contabilidade, Universidade de São Paulo.

Jones, D. N. (2014). Risk in the face of retribution: Psychopathic individuals persist in financial misbehavior among the dark triad. Personality and Individual Differences, 67, 109-113. doi: https://doi.org/10.1016/j.paid.2014.01.030.

Jones, D. N., \& Paulhus, D. L. (2014). Introducing the short dark triad (SD3): A brief measure of dark personality traits. Assessment, 21(1), 28-41. doi: https://doi.org/10.1177/1073191113514105.

Kahneman, D., \& Tversky, A. (1972). Subjective probability: A judgment of representativeness. Cognitive Psychology, 3(3), 430-454. Retrieved from: https://doi.org/10.1016/0010-0285(72)900163 doi: https://doi.org/10.1016/0010-0285(72)90016-3

Kahneman, D., \& Tversky, A. (1974). Judgment under uncertainty: Heuristics and biases. Science, New Series, 185(4.157), 1.124-1.131.

Kahneman, D., \& Tversky, A. (1979). Prospect theory: An analysis of decision under risk. Econometrica, 47(2), 263-291. doi: https://doi.org/10.2307/1914185.

Kimura, H., Basso, L. F. C., \& Krauter, E. (2006). Paradoxos em finanças: Teoria moderna versus finanças comportamentais. Revista de Administração de Empresas, 46(1), 41-58. doi: https://doi. org/10.1590/S0034-75902006000100005.

Kühberger, A., \& Tanner, C. (2010). Risky choice framing: Task versions and a comparison of prospect theory and fuzzy-trace theory. Journal of Behavioral Decision Making, 23(3), 314-329. doi: https://doi.org/10.1002/bdm.656.

Lakey, C. E., Rose, P., Campbell, W. K., \& Goodie, A. S. (2008). Probing the link between narcissism and gambling: The mediating role of judgment and decision-making biases. Journal of Behavioral Decision Making, 21(2), 113-137. doi: https://doi.org/10.1002/bdm.582.

Lauriola, M., \& Levin, I. P. (2001). Personality traits and risky decision-making in a controlled experimental task: An exploratory study. Personality and Individual Differences, 31(2), 215-226. doi: https://doi.org/10.1016/S0191-8869(00)00130-6.

Lima Filho, R. N., de Souza, A. A. C., \& D'Souza, M. F. (2019). Narcissistic personality traits in the context of accounting education: An application of the item response theory. Revista Universo Contábil, 15(2).

Lima, G., Avelino, B., \& Cunha, J. (2018). Narcisismo: Estudantes de contabilidade estão usando seu narcisismo Para melhorar o desempenho? Revista de Contabilidade e Organizações, 11(31), 58-74. doi: https://doi.org/10.11606/rco.v11i31.137775.

Magalhães, M., \& Koller, S. H. (1994). Relações entre narcisismo, sexo e gênero. Arq. bras. Psicol, 46(3/4), 77-93.

Majors, T. M. (2016). The interaction of communicating measurement uncertainty and the dark triad on managers' reporting decisions. The Accounting Review, 91(3), 973-992. doi: https//doi.org/10.2308/accr-51276.

Meisel, M., Ning, H., Campbell, W. K., \& Goodie, A. S. (2015). Narcissism, overconfidence, and risk taking in U.S. and chinese student samples. Journal of Cross-Cultural Psychology, 47(3), 385-400. doi: https://doi.org/10.1177/0022022115621968.

Moreno, K., Kida, T., \& Smith, J. F. (2002). The impact of affective reactions on risky decision making in accounting contexts. Journal of Accounting Research, 4O(5), 1331-1349. doi: https://doi.org/ 10.1111/1475-679X.t01-1-00056. 
Olsen, K. J., Dworkis, K. K., \& Young, S. M. (2014). CEO narcissism and accounting: A picture of profits. Journal of Management Accounting Research, 26(2), 243-267. doi: https:/doi.org/10.2308/jmar-50638.

Raskin, R., \& Hall, C. S. (1979). A narcissistic personality inventory. Psychological Reports, 45(2), 590. doi: https://doi.org/10.2466/pr0.1979.45.2.590.

Raskin, R., \& Terry, H. (1988). A principal-components analysis of the narcissistic personality inventory and further evidence of its construct validity. Journal of Personality and Social Psychology, 54(5), 890-902. doi: https://doi.org/10.1037/0022-3514.54.5.890.

Reche, R. A., Bertolini, A. L., \& Debona, R. R. (2020). O narcisismo do consumidor e as estratégias de marketing: Uma abordagem teórica. Revista Brasileira de Gestão e Inovação (Brazilian Journal of Management \& Innovation), 7(3), 165-184.

Reyna, V. F., \& Brainerd, C. J. (1991). Fuzzy-trace theory and framing effects in choice: Gist extraction, truncation, and conversion. Journal of Behavioral Decision Making, 4(4), 249-262. doi: https://doi. org/10.1002/bdm.3960040403.

Reyna, V. F., \& Brainerd, C. J. (1995). Fuzzy-trace theory: An interim synthesis. Learning and Individual Differences, 7(1), 1-75. doi: https://doi.org/10.1016/1041-6080(95)90031-4.

Reyna, V., Lloyd, F., \& Brainerd, C. (2003). Memory, development, and rationality: An integrative theory of judgment and decision making. nS. Schneider, \& J. Shanteau, (Eds), Emerging perspectives on judgment and decision research (cambridge series on judgment and decision making, pp. 201-245. Cambridge: Cambridge University Press. I doi:https://doi.org/10.1017/ CBO9780511609978.009.

Simon, H. A. (1955). A behavioral model of rational choice. The Quarterly Journal of Economics, 69(1), 99-118. doi: https://doi.org/10.2307/1884852.

Simon, H. A. (1963). A capacidade de decisão e liderança, Rio de Janeiro: Usaid. Obra originalmente publicada sob o título The New Science of Management Decision. New York, NY: Harper and Row, 1960).

Soane, E., \& Chmiel, N. (2005). Are risk preferences consistent? The influence of decision domain and personality. Personality and Individual Differences, 38(8), 1781-1791. doi: https://doi.org/10.1016/ j.paid.2004.10.005.

Tversky, A., \& Kahneman, D. (1981). The framing of decisions and the psychology of choice. Science, 211(4481), 453-458. doi: https://doi.org/10.1126/science.7455683.

Von Neumann, J., \& Morgenstern, O. (1944). Game theory and economic behavior, Princeton: Princeton University.

Weller, J. A., \& Thulin, E. W. (2012). Do honest people take fewer risks? Personality correlates of risktaking to achieve gains and avoid losses in HEXACO space. Personality and Individual Differences, 53(7), 923-926. doi: https://doi.org/10.1016/j.paid.2012.06.010.

Yang, Z., Sedikides, C., Gu, R., Luo, Y. L., Wang, Y., \& Cai, H. (2018). Narcissism and risky decisions: A neurophysiological approach. Social Cognitive and Affective Neuroscience, 13(8), 889-897. doi: https://doi.org/10.1093/scan/nsy053.

Yoshinaga, C. E., \& Carvalho, T. B. (2014). Finanças comportamentais no brasil: Uma aplicação da teoria da perspectiva em potenciais investidores. Revista Brasileira de Gestão de Negócios, 16(53), 594-615.

\section{Corresponding author}

Márcia D’Souza can be contacted at: marciafdsouza@yahoo.com.br

Associate Editor: Renata Schirrmeister

For instructions on how to order reprints of this article, please visit our website:

www.emeraldgrouppublishing.com/licensing/reprints.htm

Or contact us for further details: permissions@emeraldinsight.com 